\section{Growing pains}

\section{Stuart Sutherland}

Human Change Processes: The Scientific Foundations of Psychotherapy. By Michael J. Mahoney. Basic Books: 1991. Pp.590. $\$ 45$.

SCIENCE has two main aspects, the systematic recording of observations and the construction of rigorous theories to explain them. The subtitle of Human Change Processes: The Scientific Foundations of Psychotherapy should constitute an offence under the Trades Descriptions Act: there is nothing in the whole book that remotely resembles either the data or the theories of science. It is the sort of book that brings psychology into disrepute, which is a pity as even on the difficult problem of psychotherapy one or two facts have been established, even if there is still nothing meriting the name of theory.

The book starts with a potted history of philosophy, ranging from Heraclitus (who you will remember never stepped into the same river twice) to Kant. Next, it purports to give a history of 'Scientific Studies of Human Learning and Development'. Although the word 'scientific' keeps popping up in unexpected places, we are treated only to a stream of opinions, many of them banal, such as "David Foulkes studied the dreams of 150 children ... That research [perish the word] has portrayed dreams as ... predominantly based in (or drawing upon) what we know and remember". Here is another of Michael Mahoney's insightful conclusions: "To sum up, there is no question that memory and what we experience as mental representations are important phenomena in our lives." He fares no better with the "theories' he reviews, an activity he describes as 'metatheorising'. "Constructionism has been used with two different meanings: as a portrayal of the organism as an active agent in its own ongoing development, and as a means of highlighting the social contexts that construct and orient our efforts at knowing, communicating, and becoming." When translated into English, this would appear to mean that social scientists believe that although we are influenced by others, we take our own decisions.

Mahoney provides little in the way of argument. He supports his idea that "self examination is important in optimal psychotherapy" by presenting the results of a poll he conducted among psychotherapists: 2,000 psychotherapists cannot be wrong. Or again, he conveys the depressing news that "there are now dozens of distinguishable theories of emotionality, hundreds of volumes devoted to that topic, and tens of thousands of articles dealing with various aspects of human affect." He does not stoop to tell his readers what has been found out about the emotions, perhaps wisely for almost nothing worth knowing has been discovered.

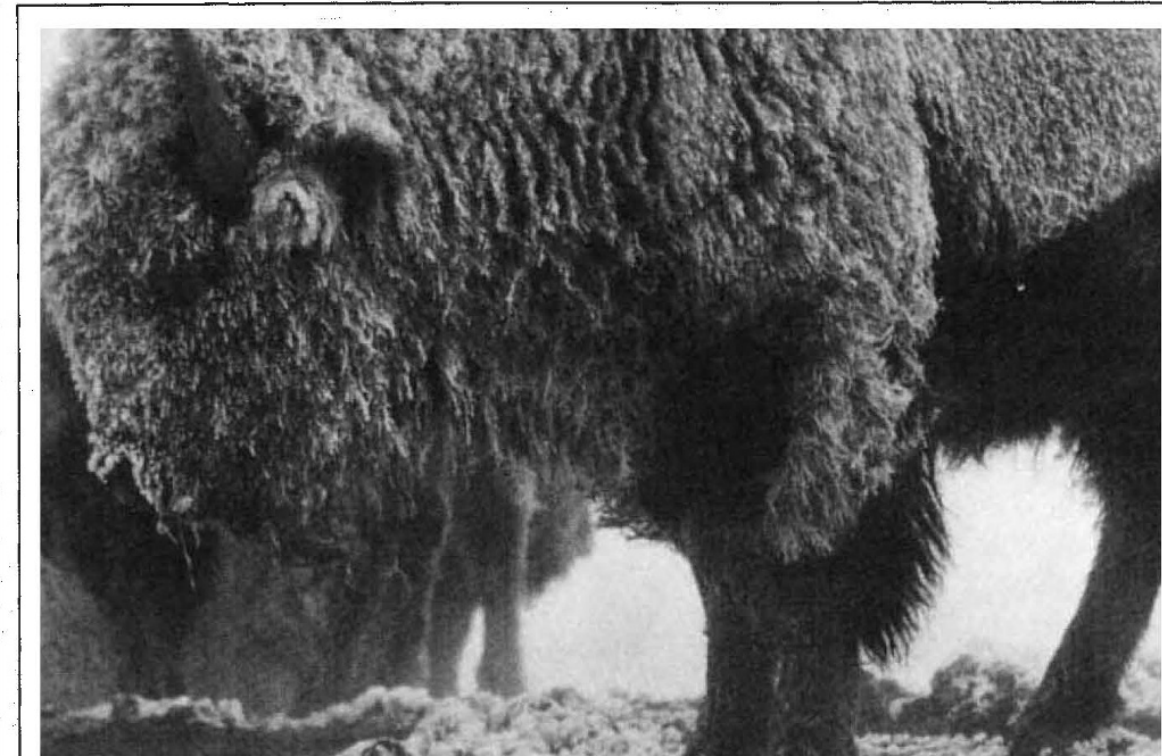

The American bison - about 50,000 remain from an original population of 60 million. Taken from The Natural History of North America by Edward Ricciuti (Facts on File, $\$ 35, £ 18.95$ ).

Having listed the opinions on human development of everyone he can think of and having given them all a prize for their sagacity, if not for their ability to prove their point, he turns in the final section, which has nothing to do with the other two, to the techniques of psychotherapy. Apparently it helps his patients if they look at themselves in a mirror, utter a series of random thoughts, dance, meditate, have massage, play different roles, indulge in 'private dialogue' and write an autobiography (one hopes not for publication). He notes that his patients 'oscillate': remarkably, they are happier at some times than at others. Mahoney never considers such questions as whether psychotherapy is a useless self-indulgence, except possibly for the mentally disordered. The majority of its clientele in America appear to be mentally normal: they just want to 'grow'. Despite Mahoney's assertion to the contrary, it is rare to see anyone over 30 or 40 growing, though they often change for the worse. Nor does he question the desirability of examining the patient's past, which cannot be changed, rather than persuading him to examine his future over which he has some control. Mahoney complains that "Federal funding for research in the social and behavioural sciences has been reduced by $25 \%$ ". Judging by this book, the American Government has at last got something right.

He has a naive faith in his own success as a therapist. There are now many studies of the outcome of therapy: the sort he espouses, namely dynamic therapy, does no better than a placebo control group in which a sham therapist simply allows the patient to talk and occasionally makes supportive noises. Moreover, despite Mahoney's insistence on the need for training, it has been shown that completely untrained counsellors do precisely as much or as little good as those who have been trained. He is unable to understand that if you have made sacrifices to enter a profession and if you are now making a decent living out of it, you are likely to think that you are doing some good even if you are not.

Despite his ability to cover nearly 600 pages with verbiage, Mahoney is clearly a very nice man. He actually submits to psychotherapy himself because he feels that only by 'growing' and learning how to 'cope' with his problems can he be of maximum use to his patients. There is fortitude and self-sacrifice indeed.

Occasionally Mahoney says something that needs saying, perhaps after the fashion of the celebrated monkeys who wrote the whole of Shakespeare by scribbling at random. For example, he rightly attacks those psychotherapists who preach to their patients that it is all in their heads on the grounds that "The parameters responsible for the pain of starvation, rape, and oppression are not confined to the nervous system of their victims." Moreover, some of his case histories are interesting. The patient always emerges a better person, but, be warned, the case history is the modern form of fairy story.

Goodness is unfortunately not enough. Even setting aside its lack of argument or evidence, Mahoney's book is extremely pretentious. 'Thinking' becomes 'mentation', 'discussion' 'dialogue', and 'view' 'perspective': all of these words are of course usually prefaced by 'ongoing'. If scholarship were evaluated by the ratio of references to text, Mahoney would be the world's greatest scholar: even the most obvious statements are often supported by up to 40 references.

I hope I have not misjudged this book. There are after all five extremely glowing encomia on the back cover: but then they are all from psychotherapists. I rest my case. $\square$

Stuart Sutherland is in the Department of Experimental Psychology, University of Sussex, Sussex House, Falmer, Brighton. BN1 9QG, UK. 